\title{
Five-dimensional structure refinement of natural melilite, $\left(\mathrm{Ca}_{1.89} \mathrm{Sr}_{0.01} \mathrm{Na}_{0.08} \mathrm{~K}_{0.02}\right)\left(\mathrm{Mg}_{0.92} \mathrm{Al}_{0.08}\right)\left(\mathrm{Si}_{1.98} \mathrm{Al}_{0.02}\right) \mathrm{O}_{7}$
}

\section{Luca Bindi, Paola Bonazzi, Michal Dušek, Václav Petř́iček and Gervais Chapuis}

Copyright (C) International Union of Crystallography

Author(s) of this paper may load this reprint on their own web site provided that this cover page is retained. Republication of this article or its storage in electronic databases or the like is not permitted without prior permission in writing from the IUCr. 
Acta Crystallographica Section B

\section{Structural}

Science

ISSN 0108-7681
Luca Bindi, ${ }^{a}$ Paola Bonazzi, ${ }^{\text {a }}$ Michal Dušek, ${ }^{\text {b }}$ Václav Petříček $^{b_{*}}$ and Gervais Chapuis ${ }^{c}$

aDipartimento di Scienze della Terra, Università di Firenze, Via La Pira 4, I-50121 Firenze, Italy, ${ }^{\mathbf{b}}$ Institute of Physics, Academy of Sciences of the Czech Republic, Na Slovance 2, 18221 Praha, Czech Republic, and 'Université de Lausanne, Institut de Crystallographie, BSP Dorigny, $\mathrm{CH}$ 1015 Lausanne, Switzerland

Correspondence e-mail: petricek@fzu.cz

\section{Five-dimensional structure refinement of natural melilite, $\left(\mathrm{Ca}_{1.89} \mathrm{Sr}_{0.01} \mathrm{Na}_{0.08} \mathrm{~K}_{0.02}\right)\left(\mathrm{Mg}_{0.92} \mathrm{Al}_{0.08}\right)$ - $\left(\mathrm{Si}_{1.98} \mathrm{Al}_{\mathbf{0 . 0 2}}\right) \mathrm{O}_{7}$}

The structure of a crystal of natural melilite from San Venanzo, Umbria (Italy) of the general formula $X_{2} T 1(T 2)_{2} \mathrm{O}_{7}$, where $X=\mathrm{Ca}_{0.945} \mathrm{Sr}_{0.005} \mathrm{Na}_{0.04} \mathrm{~K}_{0.01}, T 1=\mathrm{Mg}_{0.92} \mathrm{Al}_{0.08}$ and $T 2=$ $\mathrm{Si}_{0.99} \mathrm{Al}_{0.01}$, has been solved and refined as an incommensurate structure in five-dimensional superspace. The structure is tetragonal, superspace group $P \overline{4} 2_{1} m: p 4 m g$, cell parameters $a=$ $7.860(1), \quad c=5.024(1) \AA$, modulation vectors $\mathbf{q}_{1}=$ $0.2815(3)\left(\mathbf{a}^{*}+\mathbf{b}^{*}\right), \mathbf{q}_{2}=0.2815(3)\left(-\mathbf{a}^{*}+\mathbf{b}^{*}\right)$. The data collection was performed on a KumaCCD diffractometer. The structure was refined from 7606 reflections to final $R=0.0481$. A special modification of the refinement program Jana2000 was necessary to take into account overlapping of satellite reflections $m \times n= \pm 1$, which could not be properly separated in the integration procedure. The final model includes modulations of the atomic positions as well as modulations of the thermal parameters. The latter are induced by strong differences in the neighbourhood of the actual modulated positions. The occupational modulation was neither significant for $X$ nor for $T 1$ sites and the sites were supposed to be occupied only by $\mathrm{Ca}$ and $\mathrm{Mg}$, respectively. As a consequence of the $\mathrm{Ca}$ and $\mathrm{O}$ positional modulations six-, seven- and eightfold Ca coordination occur throughout the structure and the thermal ellipsoid changes its shape correspondingly. The positional modulation of the atoms causes variations in the interatomic distances which, however, do not affect bondvalence sums considerably, but induce flattening and rotation in $T 1$ and $T 2$ tetrahedra, respectively.

\section{Introduction}

Minerals of the melilite group mainly consist of a solid solution of gehlenite, $\mathrm{Ca}_{2} \mathrm{Al}_{2} \mathrm{SiO}_{7}$, and åkermanite, $\mathrm{Ca}_{2} \mathrm{MgSi}_{2} \mathrm{O}_{7}$, with variable amounts of $\mathrm{CaNaAlSi}_{2} \mathrm{O}_{7}$ and $\mathrm{Ca}_{2} \mathrm{FeSi}_{2} \mathrm{O}_{7}$ components. Many melilite-type compounds of the general formula $X_{2} T 1(T 2)_{2} \mathrm{O}_{7}$ have been synthesized for a wide range of chemical composition (Röthlisberger, 1990).

The basic structure of melilite, first determined by Warren (1930), consists of a linkage of $T 1$ and $T 2$ tetrahedra forming sheets parallel to (001). The eight-coordinated $X$ cations provide the connection between adjacent layers. Hemingway et al. (1986) observed thermal anomalies in synthetic $\mathrm{Ca}_{2} \mathrm{MgSi}_{2} \mathrm{O}_{7}$. They also noticed that the set of strong main reflections was accompanied by weak satellite reflections, indicating an incommensurate modulation at room temperature. The intensity of satellite reflections decreased significantly above $358 \mathrm{~K}$ and completely disappeared at $c a 580 \mathrm{~K}$. The same phenomenon was independently observed by Seifert et al. (1987) for $\mathrm{Ca}_{2} \mathrm{MgSi}_{2} \mathrm{O}_{7}-\mathrm{Ca}_{2} \mathrm{FeSi}_{2} \mathrm{O}_{7}$ solid solutions with
Received 30 March 2001 Accepted 4 September 2001
(C) 2001 International Union of Crystallography Printed in Great Britain - all rights reserved 
Table 1

Electron microprobe analysis (means, ranges and standard deviations in $\mathrm{wt} \%$ of oxides) and atomic ratios (on the basis of five cations) for the selected crystal.

\begin{tabular}{llllll}
\hline Oxide & wt $\%$ & Range & $\sigma(\%)$ & Atom & Atomic ratios \\
\hline $\mathrm{SiO}_{2}$ & 43.75 & $43.69-43.81$ & 0.09 & $\mathrm{Si}$ & 1.980 \\
$\mathrm{Al}_{2} \mathrm{O}_{3}$ & 1.87 & $1.81-1.91$ & 0.05 & $\mathrm{Al}$ & 0.100 \\
$\mathrm{MgO}$ & 13.63 & $13.55-13.71$ & 0.05 & $\mathrm{Mg}$ & 0.920 \\
$\mathrm{CaO}$ & 38.93 & $38.67-39.12$ & 0.01 & $\mathrm{Ca}$ & 1.888 \\
$\mathrm{SrO}$ & 0.46 & $0.38-0.52$ & 0.04 & $\mathrm{Sr}$ & 0.012 \\
$\mathrm{Na}_{2} \mathrm{O}$ & 0.96 & $0.90-1.05$ & 0.05 & $\mathrm{Na}$ & 0.084 \\
$\mathrm{~K}_{2} \mathrm{O}$ & 0.28 & $0.22-0.34$ & 0.04 & $\mathrm{~K}$ & 0.016 \\
Total & 99.88 & & & $\sum$ & 13.960 \\
\hline
\end{tabular}

$\mathrm{Fe} /(\mathrm{Mg}+\mathrm{Fe})$ from 0 to 0.7 . They found that the temperature of the incommensurate to commensurate transition depends on the composition. Intensities of IC (incommensurate) satellites (Kimata \& Saito, 1987) and also modulation amplitude (Seifert et al., 1987) were found to be temperature dependent. Owing to the increase in atomic dynamic disorder with increasing temperature, a non-modulated melilite structure stabilizes at high temperatures. On the basis of an electron microscopy study on the synthetic $\mathrm{Ca}_{2} \mathrm{ZnGe}_{2} \mathrm{O}_{7}$, Van Heurck et al. (1992) interpreted the modulation of the structure as caused by the formation of microdomains related to rotations and tilts of corner-sharing $T 1$ and $T 2$ tetrahedra. The modulated structures of synthetic $\mathrm{Ca}_{2} \mathrm{CoSi}_{2} \mathrm{O}_{7}$ (Hagiya et al., 1993) and $\mathrm{Ca}_{2}\left(\mathrm{Mg}_{0.55} \mathrm{Fe}_{0.45}\right) \mathrm{Si}_{2} \mathrm{O}_{7}$ (Kusaka et al., 1998) were determined using the five-dimensional superspace representation based on the method of Janner et al. (1983). In both cases the modulation arises from positional rather than substitutional disorder. In particular, the coordination number of calcium varying from six to eight as well as the flattening of $T 1$ tetrahedra appear to be the main reasons for modulation. A similar result was reported by Riester et al. (2000) for commensurate $(3 \times 3 \times 1) \mathrm{Ca}_{2} \mathrm{CoSi}_{2} \mathrm{O}_{7}$ at $130 \mathrm{~K}$. On the basis of the results derived from an electron microscope imaging and electron diffraction study of $\left(\mathrm{Ca}_{1}-{ }_{x} \mathrm{Sr}_{x}\right)_{2} \mathrm{MgSi}_{2} \mathrm{O}_{7}(0.04<$ $x<0.32$ ), Jiang et al. (1998) showed that an occupational modulation also contributes to the overall modulation characteristics, as a consequence of the ordered distribution of Sr. Accordingly, Bagautdinov et al. (2000) found a sinusoidal form of the occupancy modulation of $\mathrm{Sr}$ and $\mathrm{Ca}$ in the incommensurately modulated structure of $\left(\mathrm{Sr}_{0.13} \mathrm{Ca}_{0.87}\right)_{2} \mathrm{CoSi}_{2} \mathrm{O}_{7}$. A formal view to the problem of modulated melilites was provided by McConnell (1999), who indicated the coexistence of two structurally distinct components $\left(P \overline{4}\right.$ and $P 2_{1} 2_{1} 2$ in the incommensurate phase).

Röthlisberger et al. (1990) pointed out the role of the chemical composition in the stabilization of the incommensurate phase. According to these authors, the greater the dimensions of the tetrahedra with respect to $X$ polyhedra, the greater the structural misfit leading to an incommensurate structure. Therefore, with calcium occupying the $X$ site and divalent cations such as $\mathrm{Mg}, \mathrm{Fe}, \mathrm{Co}, \mathrm{Zn}$ filling the $T 1$ site, a modulation occurs. On the other hand, with larger amounts of smaller cations (i.e. aluminium) in the $T 1$ site, IC satellites are not observed. Probably due to the role of the isomorphous substitutions, natural melilites do not adopt incommensurate modulation. Up to now, in natural melilites, IC satellites have only been described for the hardystonite from the Franklin Furnace, with the chemical composition close to the $\mathrm{Ca}_{2} \mathrm{ZnSi}_{2} \mathrm{O}_{7}$ end-member (Bindi et al., 2001). We therefore investigated a sample of melilite from San Venanzo, Umbria (Italy), exhibiting a chemical composition close to the åkermanite end-member (Conticelli \& Peccerillo, 1992). In this paper the modulated structure of the present mineral is reported as well as a comparison with previously determined synthetic melilite-type compounds (Hagiya et al., 1993; Kusaka et al., 1998; Bagautdinov et al., 2000).

\section{Occurrence and chemical composition}

For the present study, melilite originates from a kamafugitic rock occurring at San Venanzo, Umbria (Italy). According to Conticelli \& Peccerillo (1992), kamafugites are strongly silica under-saturated (larnite-normative) and exhibit low contents of $\mathrm{Al}_{2} \mathrm{O}_{3}$ and $\mathrm{Na}_{2} \mathrm{O}$, and high contents of $\mathrm{CaO}, \mathrm{K} / \mathrm{Na}$ and $(\mathrm{Na}+$ $\mathrm{K}) / \mathrm{Al}$. The most mafic rocks of this suite consist of potassic olivine-melilitites and melilitites. Melilite occurs as a minute phenocryst associated with sanidine, olivine, augite, perovskite and opaque oxides in a microcrystalline groundmass also made up of apatite, leucite and magnetite.

A crystal of melilite, selected on the basis of its optical and diffraction quality, was embedded in resin and investigated with an electron microprobe to obtain chemical data. Replicate analyses on different spots were performed using a Jeol JXA 8600 electron microprobe operating at $10 \mathrm{kV}$ and $15 \mathrm{nA}$. The crystal appeared to be homogeneous within analytical error. On the basis of the data given in Table 1, the following chemical formula has been obtained: $\left(\mathrm{Ca}_{1.89} \mathrm{Sr}_{0.01-}\right.$ $\left.\mathrm{Na}_{0.08} \mathrm{~K}_{0.02}\right)\left(\mathrm{Mg}_{0.92} \mathrm{Al}_{0.08}\right)\left(\mathrm{Si}_{1.98} \mathrm{Al}_{0.02}\right) \mathrm{O}_{7}$.

\section{Experimental}

Preliminary X-ray investigations by precession photographs revealed a diffraction pattern similar to those previously described for the modulated structure of the synthetic melilite-type compounds (Shimizu et al., 1995, and references therein). A crystal showing sharp satellites was selected for the structural study. As already observed in melilite-type modulated structures, the modulation is two-dimensional, with modulation vectors $\mathbf{q}_{1}=\alpha\left(\mathbf{a}^{*}+\mathbf{b}^{*}\right)$ and $\mathbf{q}_{2}=\alpha\left(-\mathbf{a}^{*}+\mathbf{b}^{*}\right)$. The coefficient $\alpha$ was determined by the least-squares method from the positions of 256 satellites. All reflections observed on the collected frames were indexed by five integers, hklmn, corresponding to the five-dimensional base (de Wolff, 1974) $\mathbf{h}=h \mathbf{a}^{*}+k \mathbf{b}^{*}+l \mathbf{c}^{*}+m \mathbf{q}_{1}+n \mathbf{q}_{2}$, where $\mathbf{a}^{*}, \mathbf{b}^{*}$ and $\mathbf{c}^{*}$ are the reciprocal axes of the basic structure.

The integration of reflections was performed by Kuma software (Kuma Diffraction, 2000), which allows the integration of satellite reflections. Due to the fact that $\alpha$ was very close to $1 / 4$, we could not separate (see Fig. 1) the reflections $(h, k, l, 1,1)$ and $(h, k, l, 1,-1)$ from $(h, k+1, l,-1,-1)$ and 
Table 2

Experimental details.

\begin{tabular}{|c|c|}
\hline \multicolumn{2}{|l|}{ Crystal data } \\
\hline Chemical formula & $\begin{array}{l}\left(\mathrm{Ca}_{1.89} \mathrm{Sr}_{0.01} \mathrm{Na}_{0.08} \mathrm{~K}_{0.02}\right)\left(\mathrm{Mg}_{0.92} \mathrm{Al}_{0.08}\right)- \\
\quad\left(\mathrm{Si}_{1.98} \mathrm{Al}_{0.02}\right) \mathrm{O}_{7}\end{array}$ \\
\hline Temperature (K) & 293 \\
\hline Cell setting & Tetragonal \\
\hline Superspace group & $P \overline{4} 2_{1} m: p 4 m g$ \\
\hline$a(\AA)$ & $7.860(1)$ \\
\hline$c(\AA)$ & $5.024(1)$ \\
\hline$V\left(\AA^{3}\right)$ & $310.4(1)$ \\
\hline Formula units & 2 \\
\hline$D_{x}\left(\mathrm{Mg} \mathrm{m}^{-3}\right)$ & 2.908 \\
\hline Modulation wavevectors & $\begin{array}{l}\mathbf{q}_{1}=0.2815(3)\left(\mathbf{a}^{*}+\mathbf{b}^{*}\right) \\
\mathbf{q}_{2}=0.2815(3)\left(-\mathbf{a}^{*}+\mathbf{b}^{*}\right)\end{array}$ \\
\hline Crystal form & Irregular \\
\hline Crystal size $(m m 3)$ & $5.74 \times 10^{-4}$ \\
\hline Crystal colour & Colourless \\
\hline \multicolumn{2}{|l|}{ Data collection } \\
\hline Diffractometer & Kuma/CCD \\
\hline Radiation type & Мо $K \alpha$ \\
\hline Wavelength & 0.71073 \\
\hline Absorption correction type & None \\
\hline Absorption coefficient $\mu\left(\mathrm{mm}^{-1}\right)$ & 2.330 \\
\hline Range of $h, k, l, m, n$ & $\begin{array}{l}-11 \rightarrow h \rightarrow 11 \\
-17 \rightarrow k \rightarrow 17 \\
-11 \rightarrow l \rightarrow 11 \\
-1 \rightarrow m \rightarrow 1 \\
-1 \rightarrow n \rightarrow 1\end{array}$ \\
\hline No. of measured reflections & 234702 \\
\hline No. of unique reflections & 15779 \\
\hline No. of observed reflections & 7606 \\
\hline No. of main reflections & 1736 \\
\hline $\begin{array}{l}\text { No. of satellite reflections } \\
\quad \text { for } \pm(1,0), \pm(0,1)\end{array}$ & 3833 \\
\hline $\begin{array}{l}\text { No. of satellite reflections } \\
\quad \text { for } \pm(1,1), \pm(1,-1)\end{array}$ & 2037 \\
\hline Criterion for observed reflections & $I>3 \sigma(I)$ \\
\hline$R_{\text {int }}$ & 0.0496 \\
\hline \multicolumn{2}{|l|}{ Refinement } \\
\hline Refinement on & $F$ \\
\hline$R, w R$ (all reflections) & $0.0481,0.0514$ \\
\hline$R, w R$ (main reflections) & $0.0309,0.0358$ \\
\hline$R, w R$ (satellites) for $\pm(1,0), \pm(0,1)$ & $0.0631,0.0557$ \\
\hline for $\pm(1,1), \pm(1,-1)$ & $0.0795,0.0826$ \\
\hline$S$ & 2.43 \\
\hline No. of parameters & 238 \\
\hline Weighting scheme & $w=\left[\sigma^{2}(F)+(0.01 F)^{2}\right]^{-1}$ \\
\hline$(\Delta / \text { s.u. })_{\max }$ & 0.0456 \\
\hline$\Delta \rho_{\max }\left(\mathrm{e} \AA^{-3}\right)$ & 2.49 \\
\hline$\Delta \rho_{\min }\left(\mathrm{e} \AA^{-3}\right)$ & -2.59 \\
\hline Extinction correction & None \\
\hline Source of atomic scattering factors & $\begin{array}{l}\text { International Tables for } \\
\quad \text { Crystallography (1992, Vol. C) }\end{array}$ \\
\hline
\end{tabular}

Computer programs used: Jana2000 (Petricek \& Dusek, 2000).

$(h+1, k, l,-1,1)$, respectively. Instead, we integrated those pairs of reflections together and treated their overlap by the software (see below in this article). Data were corrected for Lorentz and polarization factors, but not for absorption which was negligible due to the crystal size and low absorption coefficient. Table 2 shows the experimental details. ${ }^{1}$

\footnotetext{
${ }^{1}$ Supplementary data for this paper are available from the IUCr electronic archives (Reference: SN0014). Services for accessing these data are described at the back of the journal.
}

\section{Structure determination}

\subsection{Refinement of the average structure}

The positional parameters of the synthetic åkermanite $\mathrm{Ca}_{2} \mathrm{MgSi}_{2} \mathrm{O}_{7}$ (Yang et al., 1997) were used as starting parameters in the refinement of the average structure. Since the chemical composition is very close to that of a pure åkermanite, the scattering curves of neutral $\mathrm{Ca}, \mathrm{Mg}, \mathrm{Si}$ and $\mathrm{O}$ were used for $X, T 1, T 2$ and anion sites, respectively. The refinement quickly converged to $R=0.0437$ for 1736 main reflections $[I>3 \sigma(I)]$. Atomic coordinates and equivalent isotropic displacement parameters for the average structure are given in Table 3. The shape of the refined anisotropic displacement parameters of $\mathrm{Ca}$ and all $\mathrm{O}$ atoms revealed a strong in-plane smearing, indicating possible modulations.

\subsection{Refinement of the modulated structure}

The Laue class $(4 / \mathrm{mmm})$ and reflection conditions ( $h 0000$, $h=2 n),(h 00 m \bar{m}, h=2 n)$ and $(h h \operatorname{lm} 0, m=2 n)$ were in accordance with the previously reported structures of synthetic melilite-type compounds (Hagiya et al., 1993; Kusaka et al., 1998; Bagautdinov et al., 2000) and the same superspace group $P \overline{4} 2_{1} m$ :p $4 m g$ was chosen for the present study. Due to its periodicity in superspace, each parameter of the modulated structure can be expressed as an expansion of a Fourier synthesis

$$
\begin{aligned}
p^{\mu}\left(x_{4}, x_{5}\right)= & \sum_{n} \sum_{m}\left[p_{\mathrm{snm}}^{\mu} \sin \left(2 \pi n x_{4}+2 \pi m x_{5}\right)\right. \\
& \left.+p_{\mathrm{cnm}}^{\mu} \cos \left(2 \pi n x_{4}+2 \pi m x_{5}\right)\right]
\end{aligned}
$$

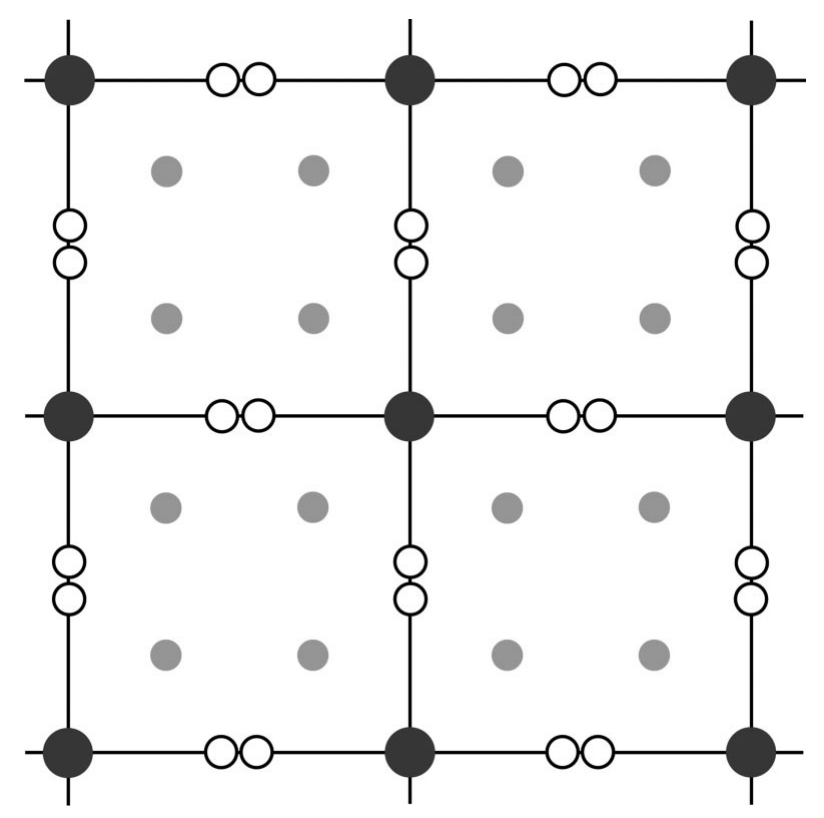

Figure 1

Schematic view of the diffraction pattern in melilite. Main reflections are indicated by large dark circles, small circles symbolize first-order satellites (grey for $m \times n=0$ and white for $m \times n= \pm 1$ satellites, respectively). 
where $x_{4}=\mathbf{q}_{1} \mathbf{r}^{\mu}+t, x_{5}=\mathbf{q}_{2} \mathbf{r}^{\mu}+u, t$ and $u$ are internal phases. Only terms having $0 \leq n \leq 1$ and $-1 \leq m \leq 1$ were used in the refinement.

As mentioned in $\$ 3$, the satellite reflections were strongly affected by overlapping. In the program Jana2000 the option for treating overlaps in the refinement has already been introduced and used in four-dimensional cases (Petricek \& Dusek, 2000; Schmid et al., 2000), but for five and six dimensions this simple approach was not applicable. Therefore, we

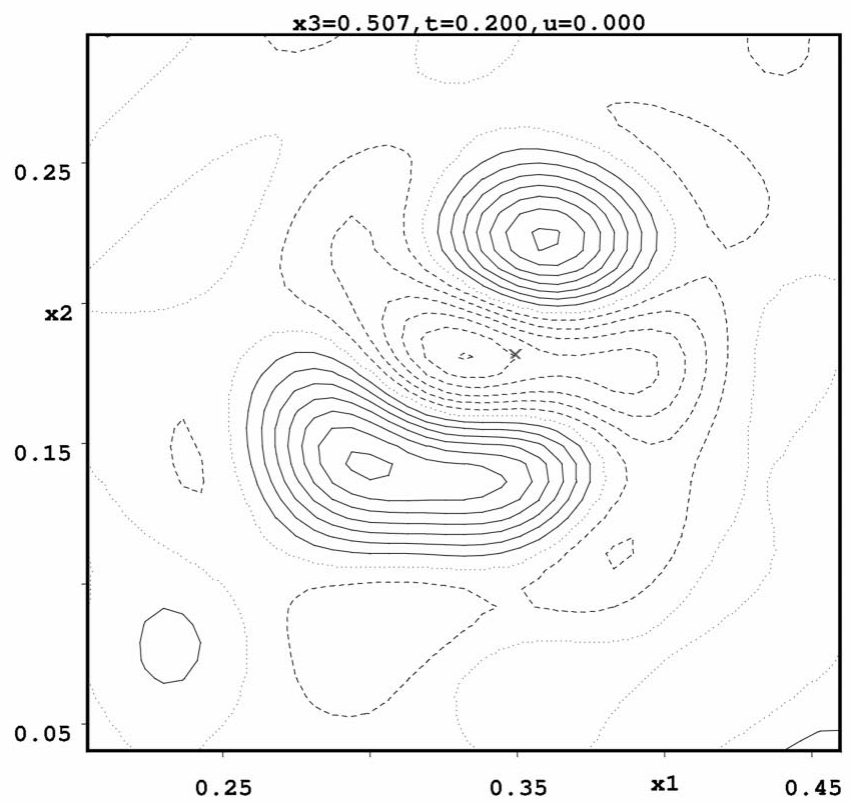

(a)

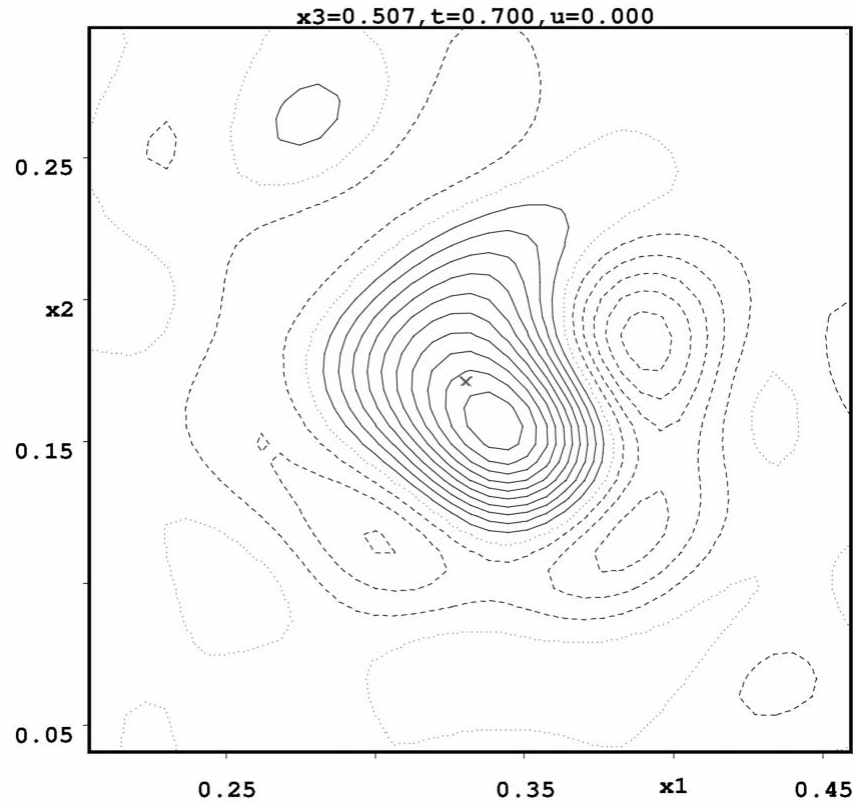

(b)

Figure 2

$x_{1}-x_{2}$ section of the electron density map through the atomic position of

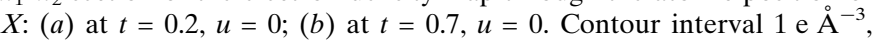
negative contour dashed, zero contour omitted.
Table 3

Fractional atomic coordinates and equivalent isotropic displacement parameters $\left(\AA^{2}\right)$ for the average structure.

$B_{\text {eq }}=\sum_{i} \sum_{j} U^{i j} \mathbf{a}_{i}^{*} \cdot \mathbf{a}_{j}^{*} a_{i} a_{j}$.

\begin{tabular}{lllll}
\hline Atom & $x$ & $y$ & $z$ & $B_{\mathrm{eq}}$ \\
\hline $\mathrm{Ca} \equiv X$ & $0.33202(3)$ & $1 / 2-x$ & $0.50616(6)$ & $0.01946(6)$ \\
$\mathrm{Mg} \equiv T 1$ & 0 & 0 & 0 & $0.01103(12)$ \\
$\mathrm{Si} \equiv T 2$ & $0.13985(4)$ & $1 / 2-x$ & $0.93536(8)$ & $0.01002(6)$ \\
$\mathrm{O} 1$ & 0 & $1 / 2$ & $0.8182(4)$ & $0.0280(4)$ \\
$\mathrm{O} 2$ & $0.14038(13)$ & $1 / 2-x$ & $0.2454(1)$ & $0.0212(2)$ \\
$\mathrm{O} 3$ & $0.0797(2)$ & $0.18673(15)$ & $0.7855(2)$ & $0.0251(2)$ \\
\hline
\end{tabular}

modified the program in such a way that it automatically checks during the refinement if in the defined neighbourhood of the calculated reflection another one exists which could also contribute to the integrated intensity. In the present case the overlap was detected just for the satellite reflections $m \times n=$ \pm 1 and it led to the following expressions for the corrected structure factors

$F_{\text {corr }, h k l 11}^{2}=F_{h k l 11}^{2}+F_{h k+1 l-1-1}^{2} \quad F_{\text {corr }, h k l 1-1}^{2}=F_{h k l 1-1}^{2}+F_{h+1 k l-11}^{2}$.

The refinement of the positional modulation of the atoms converged smoothly to $R=0.0803$. The consecutive difference Fourier maps revealed large minima and maxima close to the $\mathrm{Ca}$ atom. The most probable explanation is that in some regions, the distribution of the $\mathrm{Ca}$ atom around its refined central position is more dispersed (Fig. 2a), while in other regions it is more concentrated (Fig. $2 b$ ). This feature could also indicate split-atom positions, but with the current resolution they could not be distinguished from a continuous distribution. A similar effect was also detected for $\mathrm{O}(3)$.

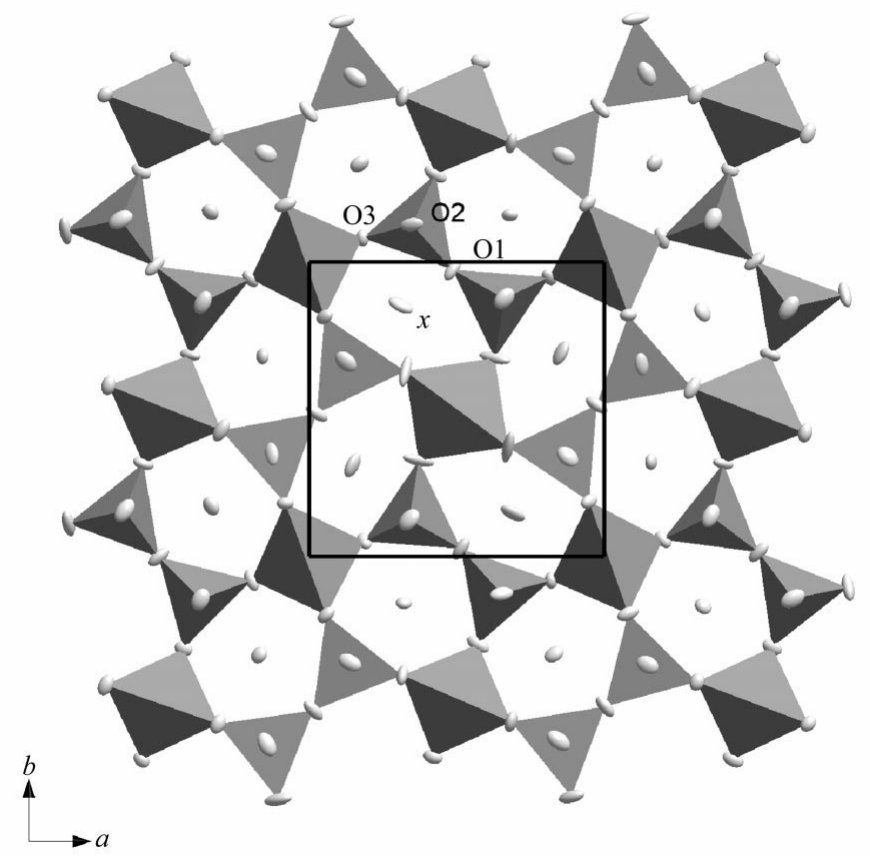

Figure 3

Projection of the structure along the $c$ axis with atoms represented by $70 \%$ probability displacement ellipsoids. The atoms $T 1$ form the larger tetrahedra. 
Table 4

Final values of coordinates and Fourier amplitudes of the displacive modulation functions and equivalent isotropic displacement parameters $\left(\AA^{2}\right)$.

The waves are sorted by the terms ( $s$ for sinus, $c$ for cosinus), $m$ and $n$.

\begin{tabular}{|c|c|c|c|c|c|}
\hline & Wave & $x$ & $y$ & $z$ & $B_{\text {eq }}$ \\
\hline \multirow{9}{*}{$\mathrm{Ca}$} & & $0.331662(18)$ & $0.168338(18)$ & $0.50694(4)$ & 0.01483 \\
\hline & $s, 1,0$ & 0.000991 (19) & -0.000991 (19) & 0.00707 (4) & \\
\hline & $c, 1,0$ & $0.00655(2)$ & $0.00655(2)$ & 0 & \\
\hline & $s, 0,1$ & $0.00295(2)$ & $0.00295(2)$ & 0 & \\
\hline & $c, 0,1$ & $0.00967(2)$ & $0.00967(2)$ & 0 & \\
\hline & $s, 1,1$ & $0.00560(3)$ & $0.00544(3)$ & -0.00555 & \\
\hline & $c, 1,1$ & 0.00109 (4) & $0.00286(3)$ & $0.00003(5)$ & \\
\hline & $s, 1,-1$ & $0.00544(3)$ & $0.00560(3)$ & 0.00555 & \\
\hline & $c, 1,-1$ & -0.00286 & -0.00109 & $0.00003(5)$ & \\
\hline \multirow[t]{9}{*}{$\mathrm{Mg}$} & & 0 & 0 & 0 & $0.00910(6)$ \\
\hline & $s, 1,0$ & -0.00331 & -0.00714 & 0 & \\
\hline & $c, 1,0$ & 0 & 0 & $0.00265(7)$ & \\
\hline & $s, 0,1$ & $0.00714(4)$ & -0.00331 & 0 & \\
\hline & $c, 0,1$ & 0 & 0 & $-0.00265(7)$ & \\
\hline & $s, 1,1$ & $0.00359(8)$ & $0.00360(8)$ & 0 & \\
\hline & $c, 1,1$ & 0 & 0 & -0.00057 (11) & \\
\hline & $s, 1,-1$ & $0.00360(8)$ & $-0.00359(8)$ & 0 & \\
\hline & $c, 1,-1$ & 0 & 0 & 0.00057 (11) & \\
\hline \multirow[t]{9}{*}{$\mathrm{Si}$} & & $0.13991(2)$ & $0.36009(2)$ & $0.93538(5)$ & 0.00825 \\
\hline & $s, 1,0$ & $0.00508(2)$ & -0.00508 & $0.00618(5)$ & \\
\hline & $c, 1,0$ & $0.00501(2)$ & $0.00501(2)$ & 0 & \\
\hline & $s, 0,1$ & $0.00042(2)$ & $0.00042(2)$ & 0 & \\
\hline & $c, 0,1$ & $0.00090(2)$ & $0.00090(2)$ & 0 & \\
\hline & $s, 1,1$ & $0.00025(5)$ & -0.00004 & $-0.00262(6)$ & \\
\hline & $c, 1,1$ & -0.00249 & -0.00275 & $0.00386(6)$ & \\
\hline & $s, 1,-1$ & -0.00004 & $0.00025(5)$ & $0.00262(6)$ & \\
\hline & $c, 1,-1$ & 0.00275 & $0.00249(5)$ & $0.00386(6)$ & \\
\hline \multirow[t]{9}{*}{$\mathrm{O} 1$} & & 0 & 0.5 & $0.8193(2)$ & $0.01582(18)$ \\
\hline & $s, 1,0$ & $0.00672(11)$ & $-0.00672(11)$ & 0 & \\
\hline & $c, 1,0$ & 0 & 0 & 0 & \\
\hline & $s, 0,1$ & $-0.01508(14)$ & $-0.01508(14)$ & 0 & \\
\hline & $c, 0,1$ & 0 & 0 & 0 & \\
\hline & $s, 1,1$ & $-0.0081(2)$ & $-0.0090(2)$ & 0 & \\
\hline & $c, 1,1$ & 0 & 0 & $0.0051(2)$ & \\
\hline & $s, 1,-1$ & $-0.0090(2)$ & $-0.0081(2)$ & 0 & \\
\hline & $c, 1,-1$ & 0 & 0 & $0.0051(2)$ & \\
\hline \multirow[t]{9}{*}{$\mathrm{O} 2$} & & $0.14059(8)$ & $0.35941(8)$ & 0.25434 (14) & $0.01657(12)$ \\
\hline & $s, 1,0$ & $0.00206(7)$ & $-0.00206(7)$ & 0.00594 (14) & \\
\hline & $c, 1,0$ & $0.01028(9)$ & $0.01028(9)$ & 0 & \\
\hline & $s, 0,1$ & $0.00209(9)$ & $0.00209(9)$ & 0 & \\
\hline & $c, 0,1$ & $0.00502(9)$ & $0.00502(9)$ & 0 & \\
\hline & $s, 1,1$ & $0.00220(15)$ & $0.00280(14)$ & $-0.00304(17)$ & \\
\hline & $c, 1,1$ & $-0.00452(18)$ & -0.00565 (14) & $0.00426(17)$ & \\
\hline & $s, 1,-1$ & $0.00280(14)$ & $0.00220(15)$ & 0.00304 (17) & \\
\hline & $c, 1,-1$ & $0.00565(14)$ & $0.00452(18)$ & $0.00426(17)$ & \\
\hline \multirow[t]{9}{*}{$\mathrm{O} 3$} & & $0.08282(9)$ & $0.18624(7)$ & $0.78834(10)$ & $0.01612(13)$ \\
\hline & $s, 1,0$ & $0.00234(10)$ & -0.00668 & 0.00674 (12) & \\
\hline & $c, 1,0$ & $0.01389(10)$ & $-0.00068(8)$ & 0.00819 (11) & \\
\hline & $s, 0,1$ & $0.01314(10)$ & -0.00478 & $0.00216(12)$ & \\
\hline & $c, 0,1$ & $0.01386(10)$ & $-0.00377(8)$ & $0.00454(11)$ & \\
\hline & $s, 1,1$ & $0.00902(16)$ & -0.00058 (14) & -0.00049 (18) & \\
\hline & $c, 1,1$ & $0.00456(16)$ & $-0.00429(13)$ & $0.0021(2)$ & \\
\hline & $s, 1,-1$ & 0.00829 & -0.00340 & $0.00340(18)$ & \\
\hline & $c, 1,-1$ & $0.00530(16)$ & $0.00087(14)$ & 0.00850 (19) & \\
\hline
\end{tabular}

Therefore, in the final refinement the modulation of the thermal parameters of all atoms was taken into account. This refinement converged to $R=0.0481$, indicating that the modulation of the thermal parameters is highly significant. The modulation of the thermal parameters of the $\mathrm{Ca}$ atom is clearly correlated with its coordination (see Fig. 3). The longest axis of the thermal ellipsoid is parallel to the elongation of the distorted pentagonal ring. On the other hand, in the centre of regular rings the Ca ellipsoids are nearly isotropic. The refined positional parameters and their modulations are given in Table 4; Table 5 reports selected interatomic distances and angles together with bond-valence sums.

\section{Discussion}

The most relevant variations observed as a function of the fourth $(t)$ and the fifth $(u)$ coordinate in superspace concern the $X$ polyhedra. The displacive modulation especially influences the longest $X-\mathrm{O} 2$ and $X-\mathrm{O} 3$ bonds, while the shortest ones are only slightly affected (Fig. 4). In particular, at $u=0.0$ the most remarkable changes are observed for the $X-\mathrm{O}^{\mathrm{i}}$ distance and to a lesser extent also for the $X-\mathrm{O}^{\mathrm{i}}$ distance. At $u=0.25$ the modulation affects the same distances, although with smaller variations than at $u=0$. Owing to this feature,

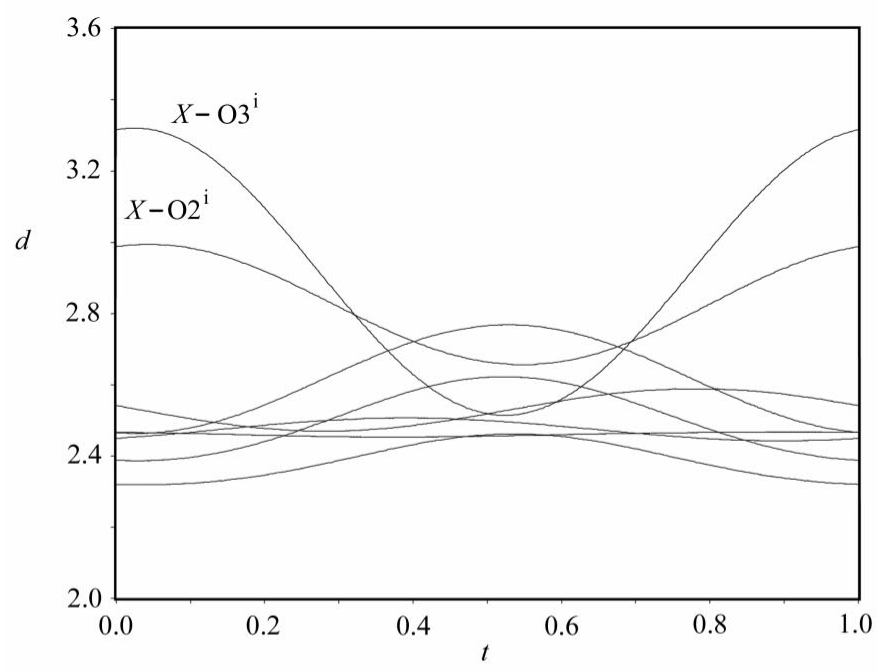

(a)

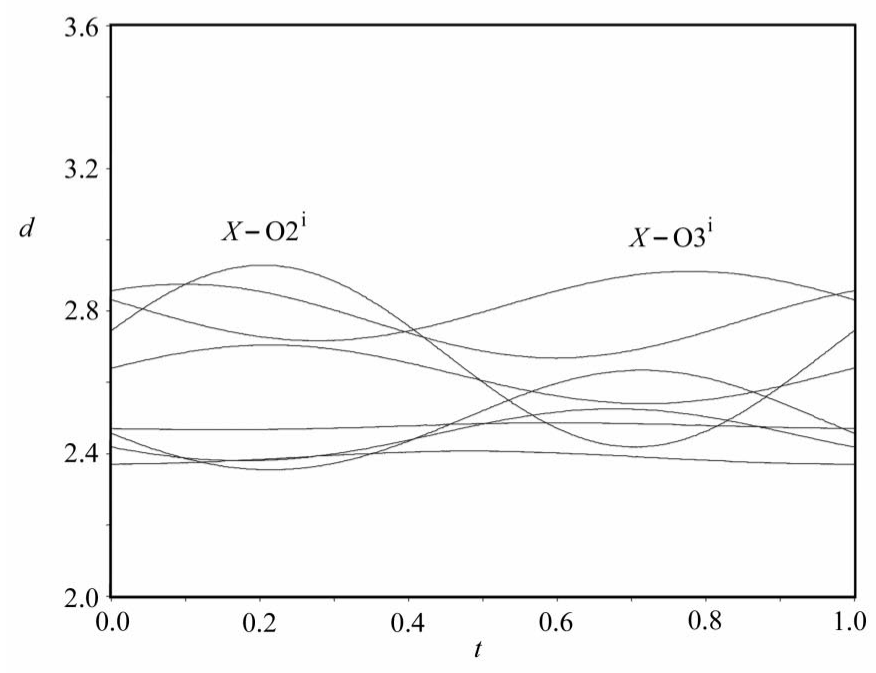

(b)

Figure 4

Variation of the $X-\mathrm{O}$ distances as functions of $t$ : $(a)$ at $u=0.0 ;(b) u=$ 0.25 . Note that only the most varying distance $X-\mathrm{O}^{\mathrm{i}}$ exceeds in some regions the limit of $2.9 \AA$. 
Table 5

The interatomic distances $(\AA)$ and tetrahedral angles $\left(^{\circ}\right)$ in the modulated structure of $\left(\mathrm{Ca}_{1.89} \mathrm{Sr}_{0.01} \mathrm{Na}_{0.08} \mathrm{~K}_{0.02}\right)\left(\mathrm{Mg}_{0.92} \mathrm{Al}_{0.08}\right)\left(\mathrm{Si}_{1.98} \mathrm{Al}_{0.02}\right) \mathrm{O}_{7}$.

\begin{tabular}{|c|c|c|c|}
\hline & Average & Minimal & Maximal \\
\hline \multicolumn{4}{|l|}{$X-\mathrm{O}$ polyhedra } \\
\hline$X-\mathrm{O} 1^{\mathrm{i}}$ & $2.494(2)$ & $2.348(2)$ & $2.650(3)$ \\
\hline$X-\mathrm{O} 2^{\mathrm{ii}}$ & $2.475(4)$ & $2.443(4)$ & $2.507(4)$ \\
\hline$X-\mathrm{O} 2^{\mathrm{i}, \mathrm{iii}}$ & $2.720(4)$ & $2.461(4)$ & $2.999(4)$ \\
\hline$X-\mathrm{O} 3^{\mathrm{ii,iv}}$ & $2.421(4)$ & $2.319(4)$ & $2.525(4)$ \\
\hline$X-\mathrm{O}^{i, \mathrm{iii}}$ & $2.726(4)$ & $2.414(4)$ & $3.321(4)$ \\
\hline Bond-valence sum & 1.701 & 1.629 & 1.836 \\
\hline \multicolumn{4}{|l|}{$T 1 \mathrm{O}_{4}$ tetrahedra } \\
\hline$T 1-\mathrm{O}^{\mathrm{i}, \mathrm{v}, \mathrm{vi}, \mathrm{vii}}$ & $1.929(4)$ & $1.912(4)$ & $1.943(4)$ \\
\hline $\mathrm{O} 3^{\mathrm{i}(\mathrm{vii})}-T 1-\mathrm{O} 3^{\mathrm{v}, \mathrm{vi}(\mathrm{v}, \mathrm{vi})}$ & $107.72(19)$ & $103.32(19)$ & $111.24(19)$ \\
\hline $\mathrm{O} 3^{\mathrm{i}(\mathrm{v})}-T 1-\mathrm{O} 3^{\mathrm{vii}(\mathrm{vi})}$ & $113.08(16)$ & $109.45(16)$ & $122.48(16)$ \\
\hline Bond-valence sum & 2.169 & 2.072 & 2.210 \\
\hline \multicolumn{4}{|l|}{$T 2 \mathrm{O}_{4}$ tetrahedra } \\
\hline$T 2-\mathrm{O} 1^{\mathrm{ii}}$ & $1.669(2)$ & $1.654(3)$ & $1.680(2)$ \\
\hline$T 2-\mathrm{O} 2^{\mathrm{viii}}$ & $1.604(2)$ & $1.597(2)$ & $1.611(2)$ \\
\hline$T 2-\mathrm{O}^{\mathrm{ii,iv}}$ & $1.623(4)$ & $1.607(4)$ & $1.656(4)$ \\
\hline $\mathrm{O} 1^{\mathrm{ii}}-T 2-\mathrm{O} 2^{\mathrm{viii}}$ & $110.87(18)$ & $110.45(18)$ & $111.37(18)$ \\
\hline $\mathrm{O} 1^{\mathrm{ii}}-T 2-\mathrm{O} 3^{\mathrm{ii}, \mathrm{iv}}$ & $102.55(18)$ & $100.57(18)$ & 104.97 (19) \\
\hline $\mathrm{O} 2^{\mathrm{viii}}-T 2-\mathrm{O}^{\mathrm{ii,iv}}$ & $116.9(2)$ & $113.8(2)$ & $118.4(2)$ \\
\hline $\mathrm{O} 3^{\mathrm{ii}}-T 2-\mathrm{O}^{\mathrm{iv}}$ & $105.3(2)$ & $104.6(2)$ & 105.7 (2) \\
\hline Bond-valence sum & 3.978 & 3.863 & 4.100 \\
\hline
\end{tabular}

Symmetry codes: (i) $y,-x, 1-z$; (ii) $x, y, z$; (iii) $\frac{1}{2}+x, \frac{1}{2}-y, 1-z$; (iv) $\frac{1}{2}-y, \frac{1}{2}-x, z$; (v) $x, y,-1+z$; (vi) $-x,-y,-1+z$; (vii) $-y, x, 1-z$; (viii) $x, y, 1+z$.

six-, seven- and eightfold coordinations of the $X$ cation occur in different parts of the structure. The change of coordination around the $X$ atom is clearly represented by the deformation of the pentagonal rings, as seen from the structure projected along the [001] axis (Fig. 5); the $T 1$ tetrahedra surrounded by

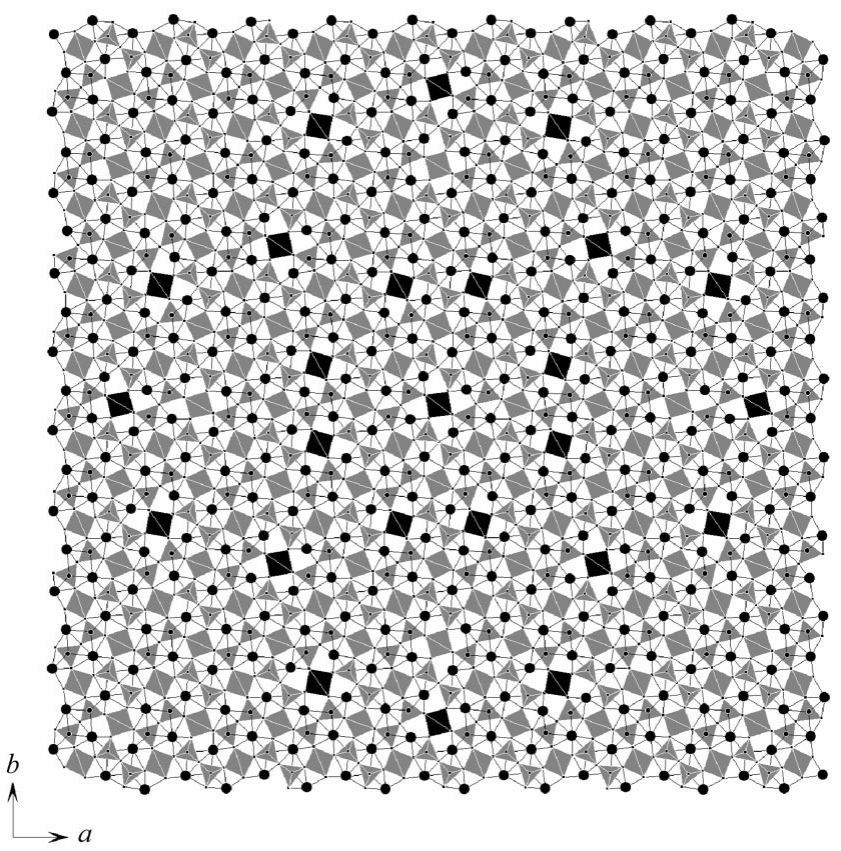

Figure 5

A portion of the modulated structure of the studied compound projected along the $c$ direction. The $T 1$ tetrahedra surrounded by eight (only four are visible in this projection) six-coordinated $X$ atoms are drawn in black. Sticks indicate $X-\mathrm{O}$ distances below $2.9 \AA$.

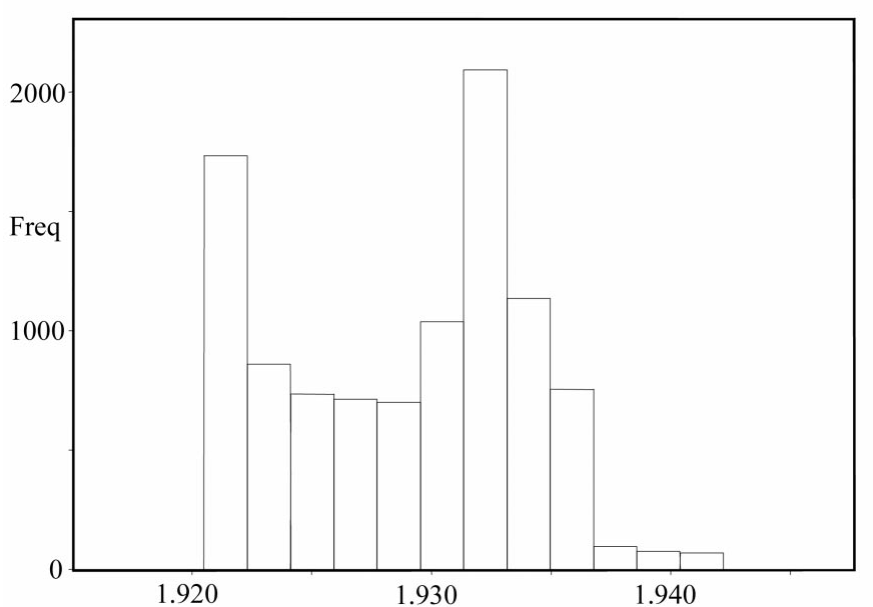

Figure 6

Histogram of the mean $T 1-\mathrm{O}$ distances in a modulation period evaluated from the modulation functions at intervals $\Delta t=0.01$ and $\Delta u=0.01$.

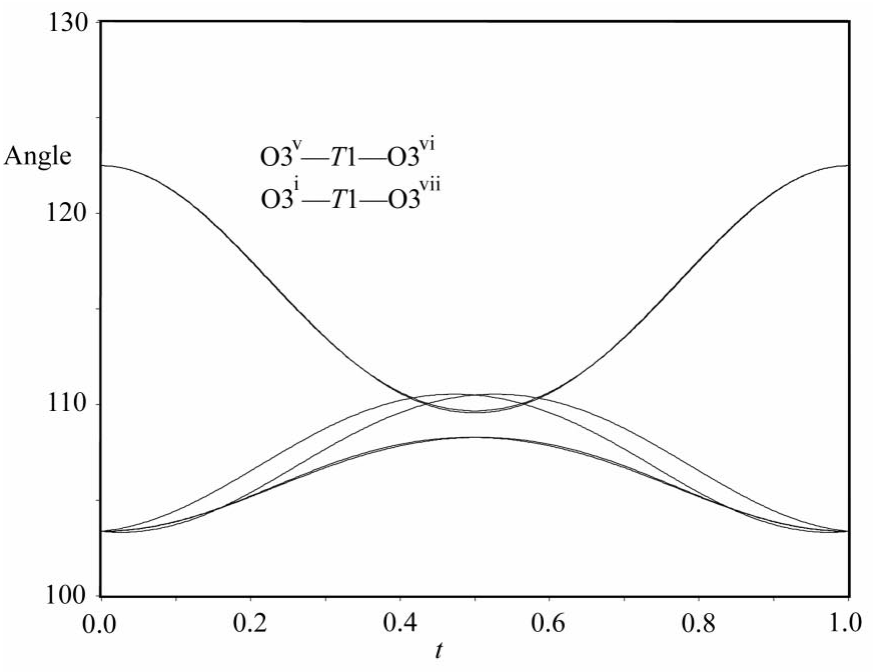

(a)

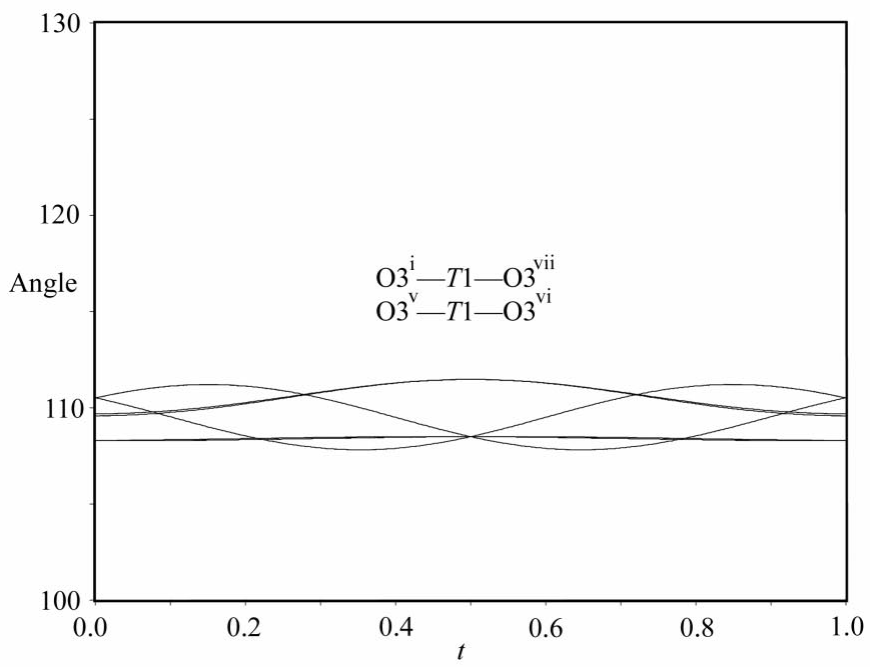

Figure 7

(b)

The variation of $\mathrm{O}-T 1-\mathrm{O}$ angles as functions of $t:(a)$ at $u=0.0 ;(b) u=$ 0.5 . The most varying angles due to flattening are labelled. 
four sixfold coordinated $X$ cations are indicated. The central part of the area represented in Fig. 5 exhibits a similar arrangement of clusters, as found by Riester et al. (2000) for the commensurate $(3 \times 3 \times 1) \mathrm{Ca}_{2} \mathrm{CoSi}_{2} \mathrm{O}_{7}$ at $130 \mathrm{~K}$. On the other hand, the octagonal distribution found by Kusaka et al. (1998) is also present.

The presence of a sixfold coordination of the $X$ cation appears to be a distinctive feature of the modulated melilite structures with the $X$ site completely occupied by calcium (Hagiya et al., 1993; Kusaka et al., 1998). In the modulated structure of $\left(\mathrm{Sr}_{0.13} \mathrm{Ca}_{0.87}\right)_{2} \mathrm{CoSi}_{2} \mathrm{O}_{7}$ (Bagautdinov et al., 2000) only sevenfold and eightfold coordinations have been

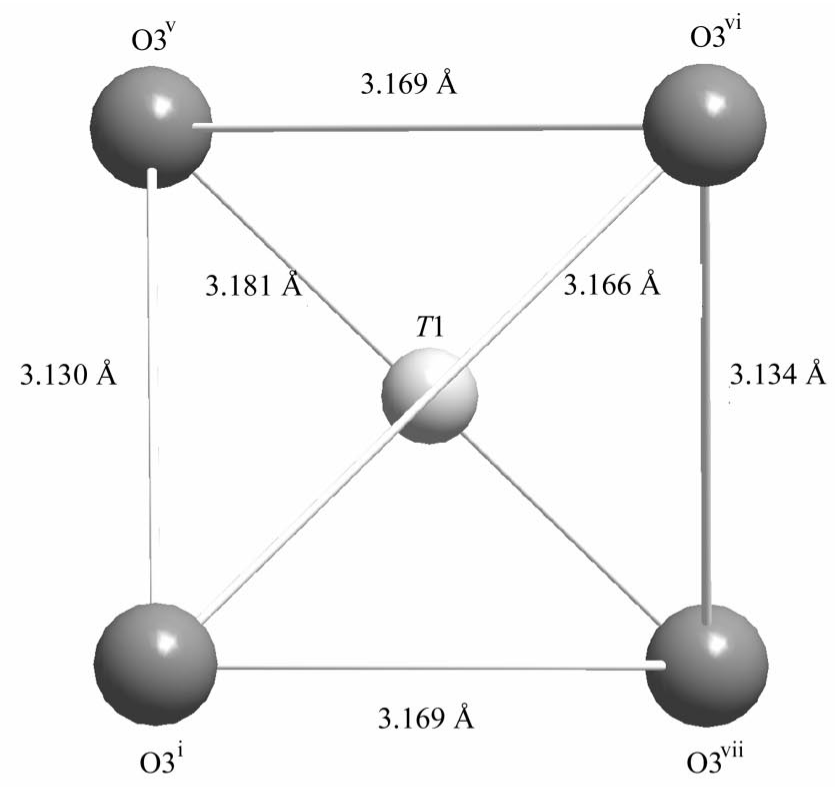

(a)

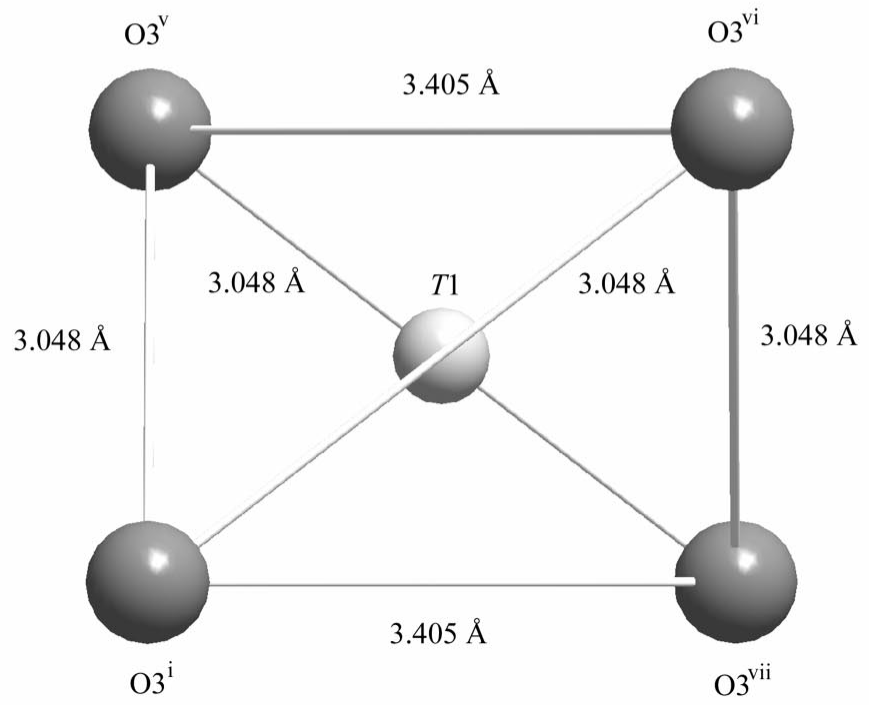

(b)

Figure 8

A $T 1$ tetrahedron viewed along $T 1$ and the midpoint between the centre of $\mathrm{O}^{\mathrm{v}}$ and $\mathrm{O} 3^{\mathrm{vi}}$ bond: $(a)$ undistorted; $(b)$ distorted. observed, as expected because of a greater hindrance of strontium. The considerable difference in the ionic radii of $\mathrm{Ca}$ and $\mathrm{Sr}$ probably causes the occupancy modulation in the structure of $\left(\mathrm{Sr}_{0.13} \mathrm{Ca}_{0.87}\right)_{2} \mathrm{CoSi}_{2} \mathrm{O}_{7}$ (Bagautdinov et al., 2000), while the introduction of $\mathrm{Na}$ replacing $\mathrm{Ca}$ does not involve any apparent ordering at the $X$ site. In keeping with this assumption, no circular diffuse scattering has been detected for the crystal examined here.

The modulation alters the $\mathrm{T} 1-\mathrm{O} 3$ distances to between 1.912 (4) and 1.943 (4) $\AA$, see Table 5. This range is less wide than in the modulated structure of Co-åkermanite (Hagiya et al., 1993). The histogram of the mean $T 1-\mathrm{O} 3$ distances calculated at steps of $\Delta t=0.01$ and $\Delta u=0.01$ shows a bimodal distribution (Fig. 6). This result corresponds with the Mössbauer spectroscopy results obtained by Seifert et al. (1987), who predicted the existence of at least two distinct environments for $\mathrm{Fe}^{2+}$ in the incommensurate structure of iron-

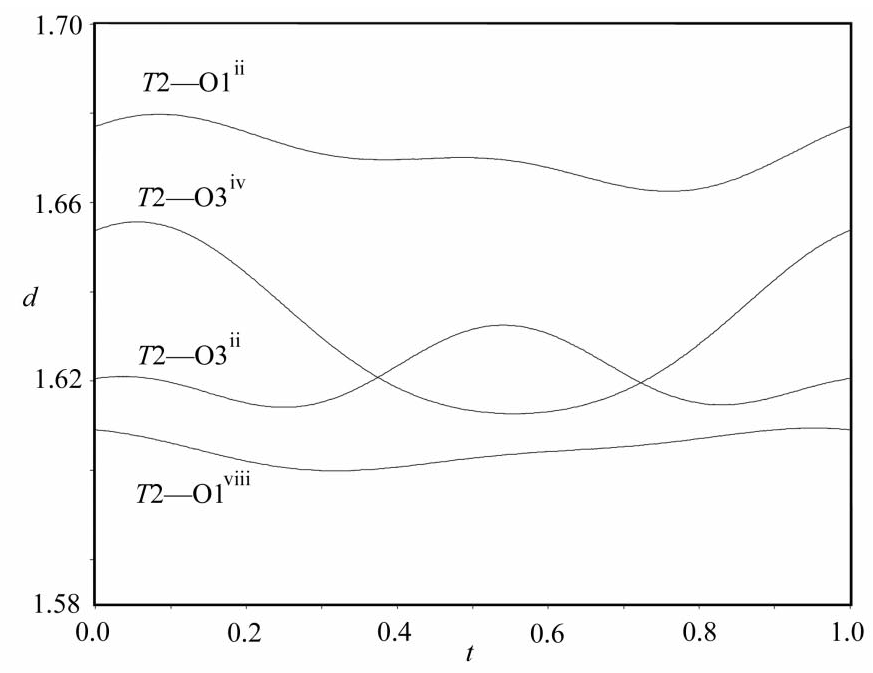

(a)

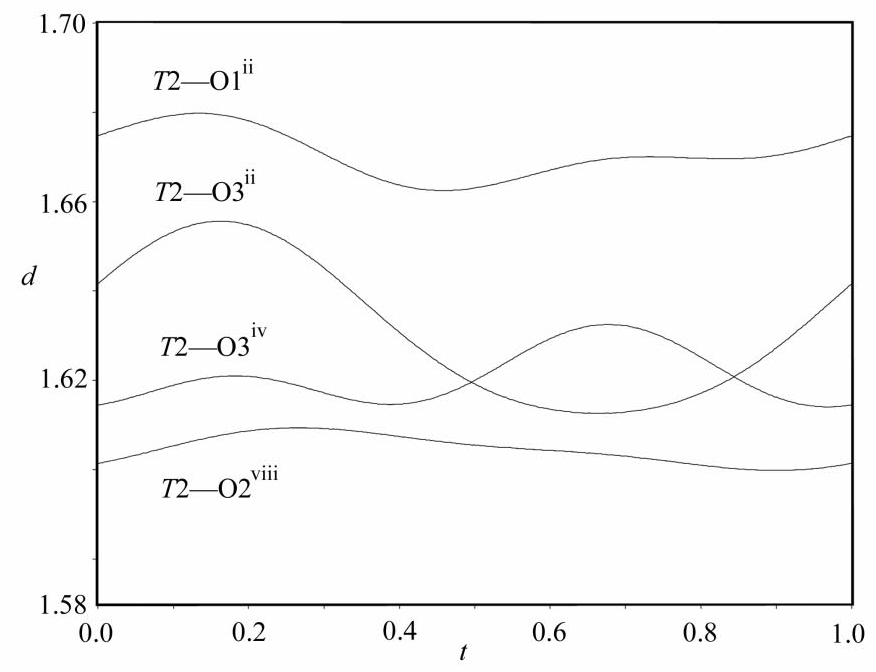

(b)

Figure 9

The variation of $T 2-\mathrm{O}$ distances as functions of $t:(a)$ at $u=0.0 ;(b) u=$ 0.5 . 
bearing åkermanites. The variation of individual $\mathrm{O} 3-T 1-\mathrm{O} 3$ angles causes strong changes in the shape of the $T 1$ tetrahedra (Fig. 7). Two of the six tetrahedral angles depart from the ideal value by $\mathrm{ca} 13^{\circ}$. The distortion clearly visible in Fig. 8 corresponds to the flattening found by Kusaka et al. (1998). The relationship between the shape of the $T 1$ tetrahedra and the surrounding pentagonal rings, respectively, can be clearly detected. In particular, the most distorted tetrahedra are surrounded by eight (only four of them are visible when viewed along $c$ axis) distorted pentagons (six- or seven-coordinated $\mathrm{Ca}$ atoms). The $T 1$ tetrahedra indicated in black in Fig. 5 are those having two tetrahedral angles larger than $117^{\circ}$.

The modulation of the $T 2$ tetrahedra (Fig. 9) has essentially a rotational character, but the shape is also affected, although not as strongly as for $T 1$. Nevertheless, the changes are significant (Table 4), causing slightly different environments for silicon. Accordingly, Merwin et al. (1989) observed a splitting into three or more lines in the ${ }^{29} \mathrm{Si}$ MAS NMR spectra of $\mathrm{Ca}_{2} \mathrm{MgSi}_{2} \mathrm{O}_{7}$, indicating that in the modulated phase the $T 2$ ions exist in three-five different sites. These signals reduce to a single one at temperatures above the transition temperature, which points to a non-modulated structure.

Finally, most of the flattened tetrahedra form octagonal clusters (Fig. 5), closely resembling the configuration derived for synthetic $\mathrm{Ca}_{2} \mathrm{ZnGe}_{2} \mathrm{O}_{7}$ by Van Heurck et al. (1992) on the basis of transmission electron microscopy.

We gratefully acknowledge the Swiss National Science Foundation (grants 20-46666.96 and 20-56870.99) and the Grant Agency of the Czech Republic (grant 202/00/0645) for supporting this project. This work was also funded by MURST, cofinanziamento 1999, project 'Transformations, reactions, ordering in minerals'.

\section{References}

Bagautdinov, B., Hagiya, K., Kusaka, K., Ohmasa, M. \& Iishi, K. (2000). Acta Cryst. B56, 811-821.
Bindi, L., Czank, M., Röthlisberger, F. \& Bonazzi, P. (2001). Am. Mineral. 86, 747-751.

Conticelli, S. \& Peccerillo, A. (1992). Lithos, 28, 221-240.

Hagiya, K., Ohmasa, M. \& Iishi, K. (1993). Acta Cryst. B49, 172179.

Hemingway, B. S., Evans, H. T. Jr, Nord, G. L. Jr, Haselton, H. T. Jr, Robie, R. A. \& McGee, J. J. (1986). Can. Mineral. 24, 425-434.

Janner, A., Janssen, T. \& Wolff, P. M. de (1983). Acta Cryst. A39, 658666.

Jiang, J. C., Schosnig, M., Schaper, A. K., Ganster, K., Rager, H. \& Tóth, L. (1998). Phys. Chem. Miner. 26, 128-134.

Kimata, M. \& Saito, S. (1987). Abstracts of the Annual Meeting of the Mineralogical Society of Japan, the Society of Mining Geologists of Japan and the Japanese Association of Mineralogists, Petrologists and Economic Geologists, p. 39.

Kuma Diffraction (2000). KM4CCD System Software, Version 1.162. Kuma Diffraction Instruments and Université de Lausanne, Switzerland.

Kusaka, K., Ohmasa, M., Hagiya, K., Iishi, K. \& Haga, N. (1998). Mineral. J. 20, 47-58.

McConnell, J. D. C. (1999). Z. Kristallogr. 214, 457-464.

Merwin, L. H., Sebald, A. \& Seifert, F. (1989). Phys. Chem. Miner. 16, 752-756.

Petricek, V. \& Dusek, M. (2000). JANA2000. Institute of Physics, Praha, Czech Republic.

Riester, M., Böhm, H. \& Petricek V. (2000). Z. Kristallogr. 215, 102 109.

Röthlisberger, F. (1990). Zusammenhang zwischen Chemismus, Stabilität und struktureller Variation der Melilite. Thesis, University of Bayreuth.

Röthlisberger, F., Seifert, F. \& Czank, M. (1990). Eur. J. Mineral. 2, 585-594.

Schmid, S., Withers, R. L., Corker, D. \& Baules P. (2000). Acta Cryst. B56, 558-564.

Seifert, F., Czank, M., Simons, B. \& Schmahl, W. (1987). Phys. Chem. Miner. 14, 26-35.

Shimizu, M., Kimata, M. \& Iida, I. (1995). Neues. Jahrb. Mineral. Monatsh. pp. 39-47.

Van Heurck, C., Van Tendeloo, G. \& Amelinckx, S. (1992). Phys. Chem. Miner. 18, 441-452.

Yang, H., Hazen, R. M., Downs, R. T. \& Finger, L.W. (1997). Phys. Chem. Miner. 24, 510-519.

Warren, B. E. (1930). Z. Kristallogr. 74, 131-138.

Wolff, P. M. de (1974). Acta Cryst. A30, 777-785. 